\title{
TINGKAT KEPATUHAN PASIEN TB PARU TERHADAP PENATALAKSANAAN PROGRAM OAT (OBAT ANTI TUBERKULOSIS) DI POLIKLINIK PARU RSUD SANJIWANI GIANYAR
}

\author{
Dewi, Ni Kadek Ayu Patni ${ }^{1}$; Pendet, Ni Made Diah P ${ }^{2 *}$ Sukarja, I Made ${ }^{3}$; \\ Krisnayani, Ni Made Wina ${ }^{4}$ \\ ${ }^{1,2,4}$ Akademi Keperawatan Kesdam IX/Udayana \\ ${ }^{3}$ Politeknik Kesehatan Denpasar \\ *Korespondensi: diahpusparinipendet@gmail.com
}

\begin{abstract}
Introduction :Tubercolosis (TB) diseases is one of the most public health problems in Indonesia. Indonesia known as a the third highest of TB cases in the world after India and China. In 2010, the Ministry of Health In Indonesia reported that patient with TB in worldwide about 5,8 \% cases was found in Indonesia. In Indonesia, TB drugs treatments called the OAT Program. The study about the interpersonal factors who can be related to the compliance of patient with TB determined how important the role of doctors and other health professionals to do verbal and non verbal communication with patients. The aim of this study was to describe complianced of patient with TB in OAT program at Sanjiwani general hospital, Gianyar. Method : This was observational descriptive study. Data were collected through questionnaires. The total of patient with TB who participated in this research were 78 collected by consecutive sampling technique. Result :Based on the research, the complianced of patient with $\mathrm{TB}$ in OAT program showed that 38 respondent $(48,71 \%)$ had complianced with the OAT program and 40 respondent $(51,28 \%)$ didn't have compliance with the OAT program. Conclusion :Most of the patient with TB in Sanjiwani general hospital didn't have compliance with OAT program.
\end{abstract}

Key words: Compliance; OAT program; Tubercolosis.

\begin{abstract}
ABSTRAK
Latar Belakang : Tuberkulosis merupakan salah satu masalah kesehatan penting di Indonesia. Selain itu, Indonesia menduduki peringkat ke-3 negara dengan jumlah penderita TB terbanyak di dunia setelah India dan China. Jumlah penderita TB di Indonesia adalah sekitar 5,8 \% pada tahun 2010 dari total jumlah penderita TB dunia. Pengobatan pasien TB dilakukan dengan program OAT. Riset tentang faktor-faktor interpersonal yang mempengaruhi kepatuhan terhadap pengobatan menunjukkan
\end{abstract}


pentingnya sensitifitas dokter dan tenaga kesehatan terhadap komunikasi verbal dan nonverbal pasien. Tujuan penelitian ini untuk menggambarkan kepatuhan pasien TB paru dalam melaksanakan program OAT di Poliklinik Paru RSUD Sanjiwani Gianyar. Metode : Jenis penelitian ini adalah observasional deskriptif. Dengan instrument yang duganakan adalah kuesioner. Pengambilan sample menggunakan teknik sampling yaitu consecutive sampling dengan jumlah sampel sebanyak 78 orang. Hasil : Pada penelitian ini hasil dari tingkat kepatuhan pasien sebanyak 38 responden $(48,71 \%)$ yang patuh dan yang tidak patuh sebanyak 40 responden (51,28\%). Simpulan : Pasien TB di Poliklinik Paru RSUD Sanjiwani Gianyar lebih banyak tidak patuh terhadap penatalaksanaan program OAT.

Kata kunci: Tuberkolosis; Kepatuhan; Program OAT

\section{PENDAHULUAN}

Semenjak tahun 2000, tuberkulosis (TB) telah dinyatakan oleh WHO sebagai remerging disease, karena angka kejadian TB yang telah dinyatakan menurun pada tahun 1990-an kembali meningkat. Meskipun demikian, untuk kasus di Indonesia, angka kejadian TB tidak pernah menurun bahkan cenderung meningkat. Di Indonesia diperkirakan setiap tahun terdapat 528.000 kasus TB paru dengan kematian sekitar 91.000 orang. Sebagian besar penderita TB paru berasal dari kelompok masyarakat usia produktif dan berpenghasilan rendah.

Zain (2001) dalam Muttaqin membagi penatalaksanaan tuberkulosis paru menjadi tiga bagian, yaitu pencegahan, pengobatan, dan penemuan penderita (active case finding).Pengobatan pada penderita TB paru selain mengobati, juga untuk mencegah kematian, kekambuhan, resistensi terhadap OAT, serta memutuskan mata rantai penularan. Penanggulangan TB Paru dilaksanakan dengan strategi Directly Observed Treatment Shortcourse (DOTS) atau pengawasan langsung menelan obat, yang dilaksanakan di Puskesmas juga melibatkan rumah sakit. DOTS adalah strategi program pemberantasan tuberkulosis paru yang direkomendasikan oleh WHO tahun 1995 (Depkes RI, 2004 ; Muttaqin, 2008).

Berdasarkan data yang diperoleh di Dinas kesehatan Provinsi Bali tahun 2010 didapatkan data TB paru sebagai berikut: yang mengalami suspek TB paru 14.738 orang, positif BTA 1.505 orang. Berdasarkan data RSUD Sanjiwani Gianyar, jumlah 
pasien TB paru yang dirawat jalan di Poliklinik Paru tahun 2010 adalah sebanyak 58 orang, tahun 2011 sebanyak 67 orang. Berdasarkan hasil pra survei dengan wawancara pada tanggal 21 Januari 2012 di Poliklinik Paru RSUD Sanjiwani Gianyar dengan 6 orang responden dari ke -6 responden didapatkan 5 orang tidak patuh terhadap pengobatan, baik dari segi jadwal obat dan keteraturan minum obat. Kendala dalam minum Obat Anti Tuberkulosis oleh karena pasien TB paru lupa untuk minum obat. Lupa minum obat disebabkan oleh pasien sibuk dalam bekerja. Tujuan penelitian ini adalah untuk mengetahui tingkat kepatuhan pasien TB Paru terhadap penatalaksanaan program OAT (Obat Anti Tuberkulosis) di Poliklinik Paru RSUD Sanjiwani Gianyar.

\section{METODE}

Desain penelitian yang digunakan dalam penelitian ini adalah observasional deskritif. Penelitian ini dilakukan di Poliklinik Paru RSUD Sanjiwani Gianyar. Penelitian dilakukan pada bulan Maret 2012 sampai April 2012. Pada penelitian ini populasinya adalah pasien TB paru yang berobat ke Poliklinik Paru RSUD Sanjiwani Gianyar. Jumlahnya adalah 97 orang. Teknik pengambilan sampel dalam penelitian ini adalah secara non probability sampling yaitu consecutive sampling. Dalam penelitian ini sampel yang diambil harus memenuhi kriteria inklusi dan eksklusi. Kriteria inklusi (kriteria yang layak diteliti), pasien TB paru yang berobat di Poliklinik Paru RSUD Sanjiwani Gianyar, mendapat pengobatan OAT, usia > 12 tahun, yang bersedia diteliti dengan menandatangani lembar persetujuan. Kriteria eksklusi (kriteria yang tidak layak diteliti) yaitu, tiba-tiba mengalami batuk berdahak, yang mengalami gangguan komunikasi.

Jenis data yang dikumpulkan berupa data primer dengan menggunakan lembar kuesioner Data primer tersebut meliputi kepatuhan pasien TB paru dalam minum OAT yang meliputi kepatuhan dalam jenis, jumlah, dan jadwal minum obat. Proses pengambilan data dimulai dengan menentukan sampel yang memenuhi kriteria inklusi. Langkah-langkah pengolahan data adalah pemeriksaan kelengkapan dan kejelasan data, pemberian kode pada setiap data variabel. Untuk mengukur 
kepatuhan pasien TB paru terhadap pelaksanaan program OAT dikelompokkan menjadi dua kategori yaitu pasien TB paru "patuh" dan "tidak patuh" dengan melihat item kepatuhan pasien TB paru terhadap penatalaksanaan program OAT, skor tertinggi adalah 8-16. Data dikelompokkan dan dianalisi untuk menentukan frekuensinya kemudian ditulis dalam bentuk tabel.

\section{HASIL}

\section{Karateristik Responden}

Berdasarkan kuesioner, karakteristik responden yang dilihat adalah umur, jenis kelamin, pendidikan dan Pekerjaan. Responden TB Paru dilihat dari jenis kelamin paling banyak adalah adalah laki-laki sebanyak 42 responden dengan presentase 53,84\%. Berada pada rentang umur terbanyak adalah 46-55 tahun sejumlah 30 responden dengan presentase 38,46\%. Jika dilihat dari pendidikan dan pekerjaan, maka jenis pendidikan yang paling banyak menderita TB paru adalah pada tingkat SD sebanyak 23 responden dengan presentase 29,48 \%. Sedangkan untuk pekerjaan, jenis pekerjaan yang paling banyak respondennya menderita $\mathrm{Tb}$ paru yaitu pekerjaan lain-lain (siswa, mahasiswa, tidak bekerja) sebanyak 36 responden dengan presentase $46,15 \%$.

\section{Tingkat Kepatuhan Pasien TB Paru Terhadap Penatalaksanaan Program OAT}

Kepatuhan Pasien TB paru dikategorikan menjadi dua yaitu patuh dan tidak patu terhadap program OAT, seperti yang terlihat pada gambar di bawah ini:

Tabel 1. Tingkat Kepatuhan Pasien TB Paru Terhadap Penatalaksanaan Program OAT di Poliklinik Paru RSUD. Sanjiwanio Gianyar

\begin{tabular}{ccc}
\hline Tingkat Kepatuhan & Jumlah $(\mathbf{n})$ & Presentase $(\%)$ \\
\hline Patuh & 38 & 48.71 \\
Tidak Patuh & 40 & 51.28
\end{tabular}

Dari tabel 1, menunjukkan bahwa dari 78 responden yang patuh sebanyak 38 responden $(48.71 \%)$ dan yang tidak patuh sebanyak 40 responden $(51.28 \%)$. 


\section{Analisa Tingkat Kepatuhan Berdasarkan Karakteristik Responden}

Berdasarkan hasil kuesioner tingkat kepatuhan dihubungkan dengan karakteristik responden. Yang mana karakteristik responden yang dilihat adalah umur, jenis kelamin, pendidikan dan pekerjaan. Lebih rincinya dapat dilihat pada tabel di bawah ini.

Tabel 2. Tingkat Kepatuhan Pasien TB Paru Terhadap Penatalaksanaan OAT Berdasarkan Karakteristik Responden Di Poliklinik Paru RSUD Sanjiwani Gianyar.

\begin{tabular}{|c|c|c|c|c|c|}
\hline \multirow{3}{*}{ No } & \multirow{3}{*}{$\begin{array}{c}\text { Karakteristik } \\
\text { Responden }\end{array}$} & \multicolumn{4}{|c|}{ Tingkat Kepatuhan } \\
\hline & & \multicolumn{2}{|c|}{ Patuh } & \multicolumn{2}{|c|}{ Tidak Patuh } \\
\hline & & $\mathbf{n}$ & $\%$ & $\mathbf{n}$ & $\%$ \\
\hline \multirow[t]{6}{*}{1} & Umur & & & & \\
\hline & $15-25$ & 6 & 15.9 & 2 & 5 \\
\hline & $26-35$ & 12 & 31.6 & 7 & 17.5 \\
\hline & $36-45$ & 13 & 34.2 & 8 & 20 \\
\hline & $46-55$ & 7 & 18.4 & 23 & 57.5 \\
\hline & Total & 38 & 100 & 40 & 100 \\
\hline \multirow[t]{4}{*}{2} & Jenis Kelamin & & & & \\
\hline & Laki-Laki & 18 & 46.15 & 24 & 61.5 \\
\hline & Perempuan & 21 & 53.8 & 15 & 38.5 \\
\hline & Total & 39 & 100 & 39 & 100 \\
\hline \multirow[t]{7}{*}{3} & Tingkat Pendidikan & & & & \\
\hline & Tidak Sekolah & 3 & 7.9 & 9 & 22.5 \\
\hline & $\mathrm{SD}$ & 7 & 18.4 & 16 & 40 \\
\hline & SMP & 10 & 26.3 & 6 & 15 \\
\hline & SMA & 13 & 34.2 & 9 & 22.5 \\
\hline & Perguruan Tinggi & 5 & 13.1 & 0 & 0 \\
\hline & Total & 38 & 100 & 40 & 100 \\
\hline \multirow[t]{6}{*}{4} & Jenis Pekerjaan & & & & \\
\hline & PNS & 10 & 26.3 & 0 & 0 \\
\hline & ABRI & 0 & 0 & 0 & 0 \\
\hline & Swasta & 16 & 43 & 16 & 40 \\
\hline & Lain-lain & 12 & 31.5 & 24 & 60 \\
\hline & Total & 38 & 100 & 40 & 100 \\
\hline
\end{tabular}

Dari tabel 2 diatas dapat dilihat bahwa karakteristik kelompok umur yang patuh paling tinggi yaitu umur 36-45 sebanyak 13 responden (34,2 \%), sedangkan kelompok umur yang tidak patuh terhadap pelaksanaan OAT paling tinggi ada pada kelompok umur 46-55 tahun sebanyak 23 responden (57,5\%). Untuk karakteristik jenis kelamin kategori patung paling banyak yaitu kelompok perempuan sebanyak 21 
responden $(53,8 \%)$ dan kategori tidak patuh paling banyak yaitu pada jenis kelamin laki-laki sebanyak 24 responden $(61,53 \%)$. Jika dilihat dari karakteristik pendidikan, responden yang patuh terhadap penatalaksanaan OAT paling banyak ada ditingkat pendidikan SMA sebanyak 13 responden $(34,2 \%)$ dan yang tidak patuh terbanyak yaitu responden yang pendidikan terakhirnya SD sebanyak 16 responden (40\%). Untuk jenis pekerjaan responden yang patuh terhadap penatalaksanaan OAT tertinggi ada pada pekerjaan swasta yaitu 16 responden (43\%) dan tertinggi dalam kategori tidak patuh ada pada pekerjaan lain-lain meliputi, siswa, mahasiswa, tidak bekerja sebanyak 24 responden $(60 \%)$.

\section{PEMBAHASAN}

\section{Karakteristik Responden}

Karakteristik responden yang dikumpulkan adalah umur, jenis kelamin, tingkat pendidikan dan jenis pekerjaan. Dari data yang diperoleh menunjukkan bahwa responden terbanyak pada karakteristik umur adalah 46-55 tahun 30 orang $(38,46 \%)$. Untuk karakteristik pendidikan yang terbanyak pendidikan SD sebanyak 22 orang $(29,49 \%)$ dan untuk pekerjaan responden yang paling banyak adalah pekerjaan lainlain diantaranya yang berprofesi sebagai siswa, mahasiswa dan tidak bekerja sebanyak 36 orang $(46,15 \%)$. Jika dilihat dari jenis kelamin, dari 78 responden terdiri dari 42 orang $(53,85 \%)$ laki-laki dan 36 orang $(46,15 \%)$ perempuan. Hal ini sesuai dengan pendapat Erawatyningsih (2009) mengatakan bahwa mayoritas penderita paru berjenis kelamin laki-laki (54,2\%). Hal ini disebabkan karena beban kerja mereka yang berat, istirahat yang kurang, serta gaya hidup yang tidak sehat di antaranya merokok dan minum alkohol.

\section{Tingkat Kepatuhan}

Kepatuhan penatalaksanaan program OAT pada pasien TB paru adalah pasien TB paru yang berobat secara tidak rutin dan terputus-putus dan tidak sampai pada waktu yang ditentukan baik dari jenis obat, jumlah obat dan jadwal obat. Berdasarkan distribusi frekuensi tingkat kepatuhan responden dalam penatalaksanaan program 
OAT pada pasien TB paru di Poliklinik Paru RSUD sanjiwani Gianyar, didapatkan bahwa 78 orang responden 38 orang $(48,72 \%)$ yang patuh dan yang tidak patuh sebanyak 40 orang $(51,3 \%)$. Hal ini dikarenakan banyak responden yang belum memahami pentingnya pengobatan TB paru. Dalam penelitian Bagiada (2010) mengatakan mengenai alasan mangkir minum obat antituberkulosis, sebagian besar penderita $(86,7 \%)$ mengeluh efek samping obat sebagian penyebabnya mangkir berobat. Efek samping yang paling sering dikeluhkan oleh penderita TB mangkir adalah keluhan pada pencernaan.

\section{Tingkat Kepatuhan Pasien TB Paru Terhadap Penatalaksanaan Program OAT Berdasarkan Karakteristik}

Dalam penelitian ini tingkat kepatuhan pasien terhadap penatalaksanaan program OAT dilihat berdasarkan karakteristik responden. Jika dilihat dari factor umur, responden yang paling banyak tidak patuh yaitu di umur 46-55 tahun dengan jumlah 23 orang $(57,5 \%)$. Sedangkan yang paling banyak patuh berada dikategori umur 26-35, 36-45 tahun yaitu $12(31,6 \%)$ dan 13 (34,2\%) responden. Hasil penelitian ini sesuai dengan pendapat Erawatyningsih (2009) mengatakan bahwa faktor umur bukan merupakan faktor penentu ketidakpatuhan penderita dalam pengobatan karena mereka yang berusia muda maupun usia lanjut memiliki motivasi untuk hidup sehat dan selalu memperhatikan kesehatan.

Berdasarkan jenis kelamin diketahui dari 42 orang responden laki-laki yang patuh 18 orang $(46,15 \%)$ dan yang tidak patuh sebanyak 24 orang $(61,5 \%)$. Untuk Perempuan sebanyak 36 orang responden yang patuh 21 orang $(53,8 \%)$ dan yang tidak patuh sebanyak 15 orang (38,5\%). Dari hasil tersebut menunjukkan bahwa lakilaki lebih tidak patuh dalam pengobatan TB paru daripada perempuan. Hal ini disebabkan karena beban kerja laki-laki yang berat, istirahat yang kurang, serta gaya hidup yang tidak sehat di antaranya merokok dan minum alkohol. Hasil penelitian ini sesuai dengan pendapat Rusmani (2007) dalam Erawatyningsih (2009) mengatakan bahwa mayoritas penderita TB paru berjenis kelamin laki-laki (54.2\%), jadi dapat dikemukakan bahwa hal ini disebabkan karena laki-laki kurang memperhatikan kesehatannya dan gaya hidup yang tidak sehat. 
Sedangkan untuk tingkat pendidikan semakin rendah tingkat pendidikan maka semakin tidak patuh pasien untuk berobat karena rendahnya pendidikan seseorang sangat mempengaruhi daya serap dan daya ingat seseorang dalam menerima informasi sehingga dapat mempengaruhi tingkat pemahaman tentang cara pengobatan dan bahaya akibat minum obat tidak teratur. Hasil penelitian ini sesuai dengan pendapat Bahar (1990) dalam Erawatyningsih (2009) menyatakan bahwa semakin tinggi pendidikan seseorang maka semakin besar kemampuan untuk menyerap, menerima atau mengadopsi informasi. Dalam penelitian ini tingkat pendidikan terendah adalah SD dan sebanyak 16 responden (40\%) masuk kategori tidak patuh.

Berdasarkan penelitian ini menunjukakan bahwa pekerjaan salah satu faktor yang mempengaruhi kepatuhan pasien TB paru terhadap penatalaksanaan program OAT di Poliklinik Paru RSUD Sanjiwani Gianyar. Hal ini disebabkan karena pasien yang berpenghasilan rendah atau tidak bekerja pendapatan atau penghasilan yang didapat masih memenuhi kebutuhan pokok sehari-hari, dan harus mengeluarkan biaya transportasi untuk berobat ke pelayanan kesehatan. Penelitian ini sesuai dengan pendapat Puwanto (2002) dalam Erawatyningsih (2009) menyatakan bahwa sosial ekonomi mempengaruhi kemampuan pembiayaan dalam bidang kesehatan karena masih terfokus kebutuhan pokoknya.

\section{SIMPULAN DAN SARAN}

Tingkat kepatuhan pasien TB paru terhadap penatalaksanaan program OAT di Poli Klinik RSUD Sanjiwani Gianyar ternyata lebih banyak pasien tidak patuh terhadap program tersebut. Ketidakpatuhan pasien TB paru dipengaruhi ooleh banyak factor salah satunya adalah karakteristik responden. Perlunya upaya penanggulangan TB paru berupa peningkatan motivasi dengan melaksanakan penyuluhan akan pentingnya pengobatan TB paru secara teratur untuk mencapai kesembuahan yang maksimal. 


\section{DAFTAR PUSTAKA}

Bagiada, I. M. \& Primasari, N. L. P. (2010). Faktor-Faktor Yang Mempengaruhi Ketidakpatuhan Penderita Tuberkulosis Dalam Berobat Di Poliklinik DOTS RSUP Sanglah Denpasar. http://ejournal.unud.ac.id/abstrak/faktor-faktor yang mempengaruhi tingkat ketidakpatuhan penderita tbc.pdf. diakses 01 Maret 2012.

Depkes R.I. (2008). Pedoman Nasional Penanggulangan Tuberkulosis Edisi 2.

Djitowiyono, S. \& Akhmad J. (2008). Hubungan Pendekatan Strategi DOTS (Direcly Observed Treatment Shortcorse) Dengan Kepatuhan Berobat Pasien Tuberkulosis. http://www.skripsistikes.wordpress.com.diakses 01 Maret 2012.

Erawatyningsih, E., Purwanta, \& Heru S. (2009). Faktor-Faktor Yang Mempengaruhi Ketidakpatuhan Berobat Pada Penderita Tuberkulosis. http://isjd.pdii.lipi.go.id/admin/jurnal/25309117124.pdf. diakses 01 Maret 2012.

Muttaqin, A. (2008). Asuhan Keperawatan dengan Gangguan Sistem Pernapasan, Jakarta, Salemba Medika.

Saryono (2010). Metodologi Penelitian Kesehatan Penuntun Praktis Bagi Pemula, Jogyakarta, Mitra Cendikia. 